\title{
Perspectives of Hospital Mortality of Intensive Cares in Public Urban Hospitals Manisa in Turkey, Based on a One-Year Review
}

\author{
Nurgül Güngör Tavsanli ${ }^{1}$ \\ 1. Celal Bayar University School
}

$\square$ Corresponding author: Nurgül Güngör Tavsanli, nurgul.gungor@hotmail.com Disclosures can be found in Additional Information at the end of the article

\section{Abstract}

Analysis of hospital mortality helps to assess the standards of health care delivery. The causes of death were coded according to the International Statistical Classification of Diseases. The causes of death were classified according to the International Statistical Classification of Diseases (ICD-10). Chi square was used to analyze. All statistical analyses were performed using the Statistical Package for the Social Sciences, Version 11 (SPSS). Of the 21,739 patients who were discharged, 300 (1.3\%) died. Males constituted $60.7 \%$ and females $39.3 \%$. The six most common ICD-10 chapters, IX, X, XIV, II, VI, and XI, included 76.4\% of the total 300 deaths. Several important issues in intensive cares were raised. Disease specific characteristics, as well as functional and infrastructural inadequacies, were identified and provided evidence for defining priorities and strategies for improving the standards of nursing care. Effective transformation can promise better prospects.

Categories: Internal Medicine, Medical Education, Epidemiology/Public Health Keywords: the international statistical classification of diseases (icd-10), mortality, icd-10, morbidity, standards of care, healthcare delivery, intensive care

\section{Introduction}

Hospital mortality is a traditional indicator for hospital performance, and under conditions in which death is not a rare event, it is a useful tool for indicating services that may present quality problems. Differences in mortality rates that are found between hospitals may occur as a function of the severity profile of the population attended. Thus, this indicator needs to be controlled and adjusted in relation to variables that might affect the result, the residual differences being the indicator for the quality of care [1-2].

Received 12/04/2012

Review began 12/04/2012

Published 12/25/2012

๑) Copyright 2012

Güngör Tavsanli. This is an open access article distributed under the terms of the Creative Commons Attribution License CC-BY 3.0., which permits unrestricted use, distribution, and reproduction in any medium, provided the original author and source are credited.
ICD-10 was endorsed by the Forty-Third World Health Assembly in May 1990 and came into use in WHO Member States as of 1994. The classification is the latest in a series that has its origins in the 1850s. The first edition, known as the International List of Causes of Death, was adopted by the International Statistical Institute in 1893. WHO took over the responsibility for the ICD at its creation in 1948 when the Sixth Revision, which included causes of morbidity for the first time, was published. The World Health Assembly adopted in 1967 the WHO Nomenclature Regulations that stipulate use of ICD in its most current revision for mortality and morbidity statistics by all Member States [3].

The International Classification of Diseases and Health Problems 10th revision (ICD-10) is a 


\section{Cureus}

standard for classifying diagnoses, symptoms, and other medical care encounters [4-5]. Reliable encoding of diagnoses is of high medical and epidemiological importance. The increasing importance of the imaging of patients' morbidity is shown by the fact that reimbursement in Turkey's ambulatory healthcare system became morbidity-based. Besides age and gender, ICD10 coded diagnoses will be the basis for this reimbursement; thus, their exact coding will be of existential relevance. There are three volumes of the ICD-10: Volume 1: Tabular list, Volume 2: Instruction manual, and Volume 3: Alphabetical index. The 21 chapters are subdivided into homogenous "blocks" of three alphanumeric character categories. This is the "core" classification of ICD-10. The four-character subcategories are recommended for many purposes and form an integral part of the ICD, as do the special tabulation lists [4, 6-7]. As of July 1, 2005, it became compulsory for health institutions in Turkey to use the ICD-10 [8].

The purpose of this study was to examine the distribution of deaths in the intensive care unit according to ICD-10 classification.

\section{Materials And Methods}

This is a retrospective cohort study evaluating the causes of deaths which occurred during the years 2008 January 1 to 2007 January 1 in single hospitals. The hospitals involved in this study were the Center Government Hospital, the Merkez Efendi Government Hospital, and Children's Hospital. The data of the study was obtained from the electronic database of each hospital. The causes of death were coded according to the International Statistical Classification of Diseases. The causes of death were classified according to the International Statistical Classification of Diseases (ICD-10) [6-7]. All statistical analyses were performed using the Statistical Package for the Social Sciences Version 11 (SPSS). Chi square was used to analyze.

\section{Ethics}

The study is based on a past-year examination of archival records and written permission was obtained between the Provincial Directorate of Health and hospital administrations. The patient names and protocol numbers of data used in the study are not disclosed.

\section{Results}

Table 1 shows the intensive care death rates in the provincial centers Manisa Centrum Government Hospital, Merkez Efendi Government Hospital, and Children's Hospital in 2007 2008 a year between the dates of distribution. Annual intensive care death rates of two government hospitals were very close.

\begin{tabular}{|c|c|c|}
\hline Hospitals & $\mathbf{n}$ & $\%$ \\
\hline Centerium Government Hospital & 150 & 50.0 \\
\hline Merkez Efendi Government Hospital & 145 & 48.3 \\
\hline Children's Hospital & 5 & 1.7 \\
\hline TOTAL & 300 & 100.0 \\
\hline
\end{tabular}

TABLE 1: Hospitals death rates 


\section{Cureus}

Of the 21,739 patients who were discharged, there were 300 (1.3\%) deaths. Males constituted $60.7 \%$ and females $39.3 \%$. Death rates in intensive care, according to gender, revealed that the male death rate was higher than women (Table 2).

\begin{tabular}{|c|c|c|}
\hline Sex & $\mathbf{n}$ & $\%$ \\
\hline Female & 118 & 39.3 \\
\hline Male & 182 & 60.7 \\
\hline TOTAL & 300 & 100.0 \\
\hline
\end{tabular}

\section{TABLE 2: Distribution of deaths by gender}

The six most common ICD-10 chapters, IX, X, XIV, II, VI, and XI, included $76.4 \%$ of the total 300 deaths. The most common contributors of non-neoplasmatic causes of death were cerebrovascular diseases (I00-I99) at 32.7\%, diseases of the digestive system (K00-K93) at 6.0\%, pulmonary diseases (J10-J18) at 12.7\%, and neurological diseases (G00-G99) at 6.0\%, accounting for $51.4 \%$ of the total 300 deaths. Neoplasms (C00-D48) caused $8.0 \%$ of the total 300 deaths, with leading forms being the malignant neoplasms of bronchus and lung (C34) at $2.9 \%$ and the malignant neoplasms of large intestine (C18.9) at $0.6 \%$ (Table 3).

\section{ICD - 10} CHAPTER

$\mathrm{A} 00$ -

B99

$\mathrm{COO}-$

2

D49

D50-

3

D89

4

E00-

E99

5

F00

F99

G00G99

H60-

8

9

10

H95

J10-
Blocks ICD-10 Title

Certain infectious and parasitic diseases

Neoplasms: all codes

Diseases of the blood and blood-forming organs and certain disorders

involving the immune mechanism

Endocrine, nutritional and metabolic diseases: all codes

Mental and behavioral disorders

Diseases of the nervous system

Diseases of the ear and mastoid process

100-199

Diseases of the circulatory system

J18 


\section{Cureus}

11

12

13

14

16

18

19

20
$\mathrm{K} 00-$

K93

LOOL99

M00M99

NOO-

N99

P00-

P96

R00-

R99

S00-

T98

V01-

Y98

External causes of morbidity and mortality elsewhere classified
18

6.0

5

Diseases of the skin and subcutaneous tissue

1

Certain conditions originating in the perinatal period

4

Symptoms, signs and abnormal clinical and laboratory findings, not

Injury, poisoning and certain other consequences of external causes

$12 \quad 4.0$

$5 \quad 1.7$

Total

\section{TABLE 3: Classification of the causes of death according to ICD-10}

The highest death rates occurred in the cardiology intensive care unit (32.7\%) and the intensive care unit (5.7\%) (Table 4). 


\section{Cureus}

\begin{tabular}{|c|c|c|}
\hline Specialty & $\mathbf{n}$ & $\%$ \\
\hline General medicine & 38 & 12.7 \\
\hline Cardiology and cardiology intensive care unit & 98 & 32.7 \\
\hline General surgery & 31 & 10.3 \\
\hline Neurosurgery & 4 & 1.3 \\
\hline Chest & 39 & 13.0 \\
\hline Nephrology & 32 & 10.7 \\
\hline Orthopedics & 8 & 2.7 \\
\hline Intensive care unit & 17 & 5.7 \\
\hline Neurology & 21 & 7.0 \\
\hline Urology & 1 & 0.3 \\
\hline Thoracic surgery & 1 & 0.3 \\
\hline Remaining specialties & 1 & 0.3 \\
\hline Hematology & 9 & 3.0 \\
\hline Total & 300 & 100.0 \\
\hline
\end{tabular}

\section{TABLE 4: Distribution of death rates per specialty}

According to Table 5 in the hospital stay time distribution of death rates is seen. Nearly complete the deaths $(83.7 \%: n=300)$ occurred by the over of the fifteen day. It is identified that over deaths have effective of long time hospitalized.

\begin{tabular}{l|ll} 
Hospitalized & $\mathbf{n}$ & $\%$ \\
\hline 15 inpatient days and less & 49 & 16.3 \\
Over 15 inpatient days & 251 & 83.7 \\
Total & 300 & 100.0
\end{tabular}

TABLE 5: The distribution of deaths from the time of admission

\section{Discussion}

In 2008, Papadopoulos NI, et al. published a retrospective cohort study evaluating the causes of 
deaths which occurred during the years 1995-1999 in a single hospital [9]. The causes of death were classified according to the International Statistical Classification of Diseases (ICD-10). Of the 149,896 patients who were discharged, there were 5,836 (3.4\%) deaths. Males constituted $55 \%$ and females $45 \%$. The median age was 75.1 years (one day - 100 years). The seven most common ICD-10 chapters, IX, II, IV, XI, XX, X, and XIV, included 92\% of the total 5,836 deaths. The causes of death were cerebrovascular diseases (160-I69) at 15.8\%, ischemic heart disease (I20-I25) at 10.3\%, cardiac failure (I50.0-I50.9) at 7.9\%, diseases of the digestive system (K00K93) at 6.7\%, diabetes mellitus (E10-E14) at 6.6\%, external +causes of morbidity and mortality (V01-Y98) at 6.2\%, renal failure (N17-N19) at 4.5\%, influenza and pneumonia (J10-J18) at 4.1\%, and certain infectious and parasitic diseases (A00-B99) at 3.2\% [9].

In 1999, Deb S. published "ICD-10 codes detect only a proportion of all head injury admissions," where a year's records between 1997 and 1998 were examined [8]. Most injuries were the age group of 18-65. Classification using ICD-10 codes were found to be more than $50 \%$ of head injuries. He determined that $46 \%$ of the hospital patients stayed $24-48$ hours [8]. This study examined the experiences of spouses of patients with ICD-10 in 2004, six female and two male patients were almost askantitif experiences. The mean age of 52, respectively. The patients' relatives of uncertainty, insecurity, and the patient had decreased protective behaviors. ICD to improve the efficiency and progress of education and psychological interventions aimed to support and strengthen the study [10].

Wockenfuss R, et al. "by the 3-4 digit ICD 10 codes for primary care classification system is not reliable" by cross sectional studies between 1999 and 2000 planned. ICD-10 sections of problems to be reliable and 34 digit codes to encode the uncertainties caused by the primary care terminology simplification should not be trusted to achieve realistic results were observed [5].

\section{Conclusions}

Several important issues in intensive cares were raised. Disease specific characteristics, as well as functional and infrastructural inadequacies, were identified and provided evidence for defining priorities and strategies for improving the standards of nursing care. Effective transformation can promise better prospects.

\section{Additional Information}

\section{Disclosures}

Human subjects: Consent was obtained by all participants in this study. The Provincial Directorate of Health and hospital administrations issued approval N/A. Animal subjects: All authors have confirmed that this study did not involve animal subjects or tissue. Conflicts of interest: In compliance with the ICMJE uniform disclosure form, all authors declare the following: Payment/services info: All authors have declared that no financial support was received from any organization for the submitted work. Financial relationships: All authors have declared that they have no financial relationships at present or within the previous three years with any organizations that might have an interest in the submitted work. Other relationships: All authors have declared that there are no other relationships or activities that could appear to have influenced the submitted work.

\section{References}

1. Iezzoni LI: Risk adjustment for medical effectiveness research: An overview of conceptual and methodological considerations. J Investig Med. 1995, 43:136-50.

2. Gomes AS, Klück MM, Riboldi R, Fachel JMG: Mortality prediction model using data from the Hospital Information System. Rev Saude Publica . 2010, 44:934-41. 
3. WHO ICD-10. (2010). Accessed: March 21, 2010: http://www.who.int/classifications/icd/en.

4. Rooney C, Griffiths C, Cook L: The implementation of ICD-10 for cause of death coding some preliminary results from the bridge coding study. Health Statistics Quarterly. 2002, 13:31-41.

5. Wockenfuss R, Frese T, Herrmann K, Claussnitzer M, Sandholzer H: Three- and four-digit ICD-10 is not a reliable classification system in primary care. Journal of Primary Health Care. 2009, 27:131. http://dx.doi.org/10.1080/02813430903072215

6. Tahir SM, Price LL, Shah PB, Welt FG : Eighteen year (1985-2002) analysis of incidence, mortality, and cardiac procedure outcomes of acute myocardial infarction in patients $>65$ years of age. Am J Cardiol. 2008, 101:930-936.

http://dx.doi.org/10.1016/j.amjcard.2007.11.040

7. ICD Gezgini. (2009). Accessed: August 20, 2009: www.saglik.gov.tr 2009.

8. Deb S: ICD-10 codes detect only a proportion of all head injury admissions . Brain Injury. 1999, 13:369-73. http://dx.doi.org/10.1080/026990599121557

9. Papadopoulos I, Papaefthymiou M, Roumeliotis L, Panagopoulos V, Anna S, Anastasia K: Status and perspectives of hospital mortality in a public urban Hellenic hospital, based on a five-year review. BMC Public Health . 2008, 8:28. http://dx.doi.org/10.1186/1471-2458-8-28

10. Albarran J, Tagney J, James J: Partners of ICD patients-an exploratory study of their experiences. European Journal of Cardiovascular Nursing . 2004, 3:201-10.

http://dx.doi.org/10.1016/j.ejcnurse.2004.06.008 